\title{
Caminhos do pensamento subjetivo para o tornar-se (inter)subjetivo: uma abordagem filosófica da linguagem
}

Maria Cristina Hennes Sampaio*

\section{Resumo}

O presente artigo tem como objetivo examinar, no âmbito de uma abordagem filosófica da linguagem, os caminhos do pensamento subjetivo para o tornar-se (inter)subjetivo. Para esse fim, colocamos em diálogo as ideias filosóficas de E. Husserl, M. Bajtin, M. Heidegger e S. Kierkegaard. As questões levantadas são sugestivas quanto à existência de projetos de conhecimento bastante distintos daqueles que conhecemos nas ciências positivas, modificando radicalmente nossa visão sobre as formas de conhecimento, os fenômenos de linguagem, a alteridade, incluindo noções de sujeito, de subjetividade e (inter)subjetividade, noção da própria história/historicidade, da forma de se pensar a noção de linguagem como aquela que detém a guarda tanto do ser das coisas como também do modo de acontecer do evento, a noção de sentido, que só pode ser encontrado no dever-ser do ato responsavelmente vivido e no ser-aí (Dasein), no acontecimento do ser e do ser-com-os-outros.

Palavras-chave: Filosofia da linguagem. Alteridade. Pensamento subjetivo. (Inter)subjetividade.

\section{Introdução}

O presente estudo faz parte do projeto Origens filosóficas da ética em Bakhtin: releituras da metafísica e da fenomenologia ontológico-hermenêutica (2012-2016), desenvolvido no âmbito dos grupos de pesquisa Linguagem, Sociedade, Saúde e Trabalho, da Universidade Federal de Pernambuco, Linguagem, Identidade e Memória, da Pontifícia Universidade Católica de São Paulo, ambos ligados ao Conselho Nacional de Desenvolvimento Científico e Tecnológico, e do Grupo de Estudos Bakhtinianos, da Associação Nacional de Pós-Graduação em Letras e Linguística, cujo objetivo é examinar, no âmbito de uma abordagem

\footnotetext{
Professora Adjunta do Departamento de Letras e do Programa de Pós-Graduação em Letras da UFPE. Doutora em Linguística e Semiótica pela USP e Pós-doutora em Linguística Aplicada e Estudos da Linguagem pela PUC-SP. E-mail: mc.hennes@hotmail.com
}

\footnotetext{
Data de submissão: mar. 2016 - Data de aceite: maio 2016 http://dx.doi.org/10.5335/rdes.v12i1.5787
} 
filosófica da linguagem, os caminhos do pensamento subjetivo para o tornar-se (inter)subjetivo.

Para esse fim, colocamos em diálogo as ideias filosóficas de Husserl ([1954] 2012), contidas na obra $A$ crise das ciências europeias e a fenomenologia transcendental, e de Bajtin, Heidegger e Kierkegaard, contidas nas obras $\mathrm{Ha}$ cia una filosofia del acto ético: de los borradores y otros escritos (BAJTIN, [1920-1924] 1997), On time and being (HEIDEGGER, [1969] 1972), Ontologia: (Hermenêutica da facticidade) (KIERKEGAARD, [1982] 2012) e Pós-escritos às migalhas filosóficas (KIERKEGAARD, [1846] 2013).

A escolha dos filósofos alemães Edmund Husserl e Martin Heidegger para dialogar com o russo Mikhail Bajtin deu-se pelo fato de que, além de serem contemporâneos, eles foram fortemente influenciados pela fenomenologia de Husserl, a ponto de Heidegger ter-lhe sucedido na cátedra, em Freiburg, em 1929. Quanto a Bajtin e Heidegger, conforme indicado por Sampaio (2012) e por Sampaio, Araújo e Macedo (2015), em publicações anteriores, além de terem preocupações filosóficas comuns, sobretudo aquelas que dizem respeito ao ser como acontecimento, o próprio Todorov, segundo Amorim (2009), já assinalara que a ideia do diálogo, como condição da linguagem, teria sua origem em Heidegger. Quanto ao dinamarquês Kierkegaard, embora seja um filósofo do século XIX, a escolha se deu pelo fato de ter exercido forte influência em Heidegger, na escritura de Ser e tempo, sua obra mais importante.

Quanto ao texto principal da obra husserliana, anteriormente referida, o filósofo vai reportar-se ao caráter duvidoso da psicologia e à crise que lhe seria própria, a qual evidenciaria uma série de obscuridades enigmáticas e sem solução das ciências modernas, em geral, que conduzem ao enigma da subjetividade e à forma de seu tratamento pelo método científico. O que a ciência teria a nos dizer, pergunta o filósofo? Para Husserl (2012), as ciências biológicas não teriam nada a nos dizer, já que elas abstraem tudo o que é subjetivo.

Quanto às ciências do espírito e suas disciplinas correlatas, essas tratariam o homem e sua existência espiritual no horizonte da historicidade e sua cientificidade rigorosa exigiria, dos pesquisadores, que eles considerassem a posição axiológica, as questões da razão e sem razão da humanidade e suas formas de cultura. Segundo Husserl, “[...] a verdade científica, objetiva, é exclusivamente a verificação daquilo que o mundo, de fato, é, tanto o mundo físico como espiritual" (2012, p. 3). Seria possível viver em um mundo no qual o acontecimento histórico seja reduzido a uma cadeia de fatos objetivos que se repetem? Nesse sentido, o autor critica o objetivismo e a pretensão de que a verdade só possa ser enunciada por meio de um sistema de proposições da ciência objetiva. 
O filósofo russo Bajtin (1997), na obra Hacia una filosofia del acto ético, escrita entre 1920 e 1924, também qualifica como teoreticismo grosseiro a tentativa da psicologia de incluir o mundo do conhecimento teórico, do ser global, "na qualidade de existência psíquica”, já que esse ser psíquico seria apenas um produto abstrato do pensamento teórico e, por conseguinte, não poderia corresponder ao ato ético de um pensamento vivo. Nesse sentido, reafirma Bajtin que "o ato ético somente se concretiza no ser" (1997, p. 20) através de mim e de outros. Segundo ele, "é impossível qualquer orientação prática" na "vida do mundo teórico" (1997, p. 16-17), já que esse é obtido por meio de uma abstração. Para o mundo teórico, a comunicação real e singular com o ser é indiferente, isso não vai modificar seu sentido e significação, que permanecerão sempre os mesmos.

Quanto ao filósofo alemão Martin Heidegger, ao referir-se ao verbo vivenciar, sugere que ele signifique "reatar, a saber, a vida e o vivido a um sujeito" (2011, p. 102), evocando a correlação entre objetivo e subjetivo. No entanto, Heidegger adverte que mesmo até a tão propalada vivência do eu-tu ainda pertenceria ao âmbito metafísico da subjetividade, já que, na filosofia e na história, o ser fala diretamente de si mesmo, ou seja, já tem uma compreensão de si mesmo, sua forma de presença no mundo é estável, fazendo coincidir o ser com o ente. Segundo ele, é preciso questionar o "ter-se-aí do ser-aí enquanto ser, enquanto o como da facticidade ${ }^{1} \mathrm{e}$ enquanto existencial"2 (2012, p. 57).

Ora, tanto na consciência histórica como na filosofia, o ser-aí é reduzido a um caráter objetivo e na modalidade de um ser permanente, determinado pela cognição, quando devemos questionar o caráter ontológico do ser-aí em sua peculiar mobilidade, ou seja, o como da temporalidade, da facticidade, ${ }^{3}$ revelados pelos existenciais na própria existência. Essa ideia de subjetividade é desconstruída por Heidegger (2012) na referência à hermenêutica da duplicidade (ser/ente), que indicia a forma pela qual o ser-aí mundano significa, tanto em seu contexto fenomenológico como em seu caráter de encontrar-se no mundo.

Ao abordar o tema, Heidegger (2010b) questiona em que medida os fenômenos com os quais nos ocupamos podem ser caracterizados historicamente. Ora, o histórico pode ter muitos sentidos, a depender de seu campo de aplicação, a saber, à ciência histórica ou à experiência fática da vida. O histórico não necessariamente ocorre no tempo ou é algo que provém de uma relação objetiva: nesse caso, trata-se de uma "propriedade de um objeto sujeito à mudança temporal, na experiência fática da vida e no aperfeiçoamento linear e ordenado da filosofia", resultando no "esvaziamento teórico-científico do fenômeno da vida" (HEIDEGGER, 2010b, p. 33). Diferentemente, pensar o histórico, na experiência fática da vida, pressupõe que "cada acontecimento espaço- 
-temporal" apresente "a propriedade de estar sujeito a uma relação de tempo e de vir-a-ser", daí o questionamento sobre "como a vida fática, a partir de si, relaciona-se com a história" (HEIDEGGER, 2010b, p. 35-37).

\section{Abordagens fenomenológica-ontológica- hermenêutica e dialógica}

Considerando que a expressão do pensamento participativo é materializado na palavra, o que equivale a dizer no texto e no discurso, o fenômeno de estudo que nos ocupa - os caminhos do pensamento subjetivo para o tornar-se (inter)subjetivo - e suas implicações para a compreensão da relação eu-outro(s) é abordado na perspectiva de uma ação dialógica, como um ato responsável, e da fenomenologia ontológica-hermenêutica. Nesse sentido, segundo Heidegger (2010a, 2012), a compreensão do ser não se resume a uma questão de ordem meramente linguística, já que, mesmo na ausência de uma enunciação, a compreensão do ser é constitutiva do ente.

Assim, uma investigação hermenêutica, no sentido heideggeriano (HEIDEGGER, 2012), pressupõe um voltar-se ao ser-aí tal como ele se mostra na vida fática (Dasein), ou seja, na existência e, exige, do pesquisador, um questionamento hermenêutico acerca da possibilidade de ser do fenômeno em questão, cujo sentido (ser) varia de acordo com a situação à qual tal questionamento é feito, em cada ocasião. Uma compreensão fática pressupõe, portanto, deixarmos de lado os nossos pré(conceitos), o cálculo e a ideia tradicional de homem, já que o caráter ontológico do ser-aí não pode ser calculado de antemão, visto que nunca pode constituir-se em uma objetulidade, mas ser, enquanto possibilidade, em uma vida e em cada ocasião (HEIDEGGER, 2012).

Quanto ao dialogismo, enquanto pressuposto conceitual-analítico, sabemos que para Bajtin pressupõe o estabelecimento de relações de sentido, que acontecem em um mundo no qual não há espaço para o ser como algo determinado, válido em si mesmo, como uma verdade fundadora de um começo do sentido, mas "apenas a infinidade da avaliação e absoluta inquietação são possíveis na perspectiva do reconhecimento de minha participação única no ser" (BAJTIN, 1997, p. 50). Por conseguinte, uma ação dialógica, como ato responsável, deve orientar-se para um conteúdo-sentido que só pode ser desvelado no acontecimento do ser e por meio do reconhecimento de nossa participação única no ser.

$\mathrm{Na}$ análise do ato responsável e do ser-aí (Dasein), Bajtin (1997) e Heidegger (2010a), respectivamente, sugerem a necessidade de demonstrar a forma como se dá a inserção/apropriação do ato e do Dasein em um mundo singular e único vivido de forma concreta, visto, ouvido, apalpado e pensado, impregnado por tonalidade afetiva/emocional e volitiva. Para Bajtin: 
[...] a singularidade do mundo não tem origem em nenhum conteúdo semântico, já que é de ordem emocional e volitiva, e o que garante a nossa participação singular, no mundo, é o nosso não-álibi no ser (1997, p. 63).

Isso significa que essa nossa participação no ser não é casual nem fortuita, mas um dever, um comprometimento, uma responsabilidade com a singularidade da existência no acontecimento do ser, a qual transforma cada manifestação nossa, em forma de pensamento, sentimento, desejo, estado de ânimo, em um ato ativo e responsável exclusivamente nosso. Além disso, a nossa participação no acontecimento do ser:

[...] cria uma gravidade real do tempo e um valor palpável e manifesto do espaço no mundo, convertendo-o num todo único e singular, real e responsavelmente vivenciado (BAJTIN, 1997, p. 64-65).

Assim, Bajtin questiona a natureza do sentido em sua durabilidade, ou seja, se a sua eternidade seria axiologicamente possível. Argumenta que se isso fosse possível, ou seja, se "a eternidade do sentido fosse axiologicamente válida, então seu raciocínio e realização efetivas, mediante o pensamento ativo, seria desnecessário", insistindo que "somente em relação com a realidade, o sentido eterno" - no nosso entendimento, aquilo que já está dado na realidade - "converte-se em força motriz do pensamento ativo" (1997, p. 65). Nesse sentido, reconhece o valor do sentido eterno, daquilo que já está dado, na totalidade do mundo já dado, que é iluminado pela luz axio- lógica de um pensamento efetivamente realizado.

\section{Fontes dos dados bibliográficos e breves comentários das obras}

As fontes de dados são textos (discursos), contidos nas obras listadas a seguir, que se encontrem em relação dialógica com o tema o pensamento subjetivo para tornar-se (inter)subjetivo:

a) BAJTIN, M. Hacia una filosofia del acto ético: de los borradores y otros escritos. Trad. Tatiana Bubnova. Barcelona: Rubi e San Juan; Antrophos, 1997. A obra foi escrita entre 1920 e 1924, e a edição em análise inclui passagens censuradas na edição russa de 1986, em que o filósofo apresenta, em uma tríade conceitual da vida/arte/ ciência, o ético/estético/cognoscitivo;

b) HUSSERL, E. A crise das ciências europeias e a fenomenologia transcendental. Trad. Diogo Falcão Ferrer. Rio de Janeiro: Forense, 2012. A publicação, em 1936, na revista $P h i$ losophia, foi resultado de conferências proferidas em Praga e representou um esforço crítico do filósofo contra os contrassensos filosóficos que, no seu entender, impediam o acesso ao verdadeiro sentido da filosofia;

c) HEIDEGGER, M. Ontologia: (Hermenêutica da facticidade). Trad. Renato Kirchner. Petrópolis: Vozes, 2012. Publicado pela primeira vez em 1982, como volume 63 de sua Gesamtausga- 
$b e$, o texto é proveniente de preleções dadas na Universidade de Freiburg, em 1923. Nele, o filósofo busca tematizar e compreender a facticidade que designa o caráter próprio do nosso ser-aí;

d) HEIDEGGER, M. El ser y el tiempo. Trad. José Gaos. 2. ed. Buenos Aires: Fundo de Cultura Econômica, 2010. A obra apareceu, pela primeira vez, em 1927, no Jahrbuch fuer Philosophie und phaenomenologische Forshung, v. VIII, dirigido por E. Husserl, e também na forma impressa de separata dessa mesma obra. Trata-se da obra mais importante da filosofia contemporânea na qual é abordada uma questão fundamental: o sentido do ser;

e) HEIDEGGER, M. On time and being. Trad. Joan Stambaugh. New York, Hagerstown, San Francisco, London: Harper \& Row, 1972. A obra contém a preleção de Tempo e Ser, juntamente com o resumo de seis seminários da preleção, O fim da filosofia e a tarefa do pensamento e um pequeno texto sobre a relação de Heidegger com a fenomenologia;

f) KIERKEGAARD, S. A. Pós-escrito às migalhas filosóficas. Trad. Álvaro Luiz Montenegro Valls e Marília Murta de Almeida. Petrópolis: Vozes, 2013. v. 1. Na obra, datada de 1846 , o filósofo, sob o pseudônimo de Johannes Climacus, revisita seu projeto existencial e autoral, comentando criticamente obras anteriores. Para o filósofo dinamarquês Poul Lübcke
(2013), Heidegger inspirou-se em Kierkegaard para elaborar Ser e tempo, embora tenha tido preocupações diferentes.

\section{Pressupostos de abordagem do acontecimento do ser}

A compreensão do acontecimento do ser passa pelos princípios de que o ser é a abertura para o mundo, e que, portanto, a compreensão que se pretende é aquela que só pode ser encontrada no dever-ser do ato responsavelmente vivido e no acontecimento do ser, do agir dialógico pelo pesquisador, que pressupõe deslocar-se do ato/ação (e contexto) contido no texto-fonte (BAJTIN, 1997), e colocá-los em relação dialógica com os atos/ações (e contextos) contidos em outros textos, assinados por outros filósofos, já que o vir-a-ser, tanto em relação ao acontecimento do ser como do sentido, inscreve-se na diferença, na relação de alteridade que se estabelece entre o eu e o outro.

A operacionalização do método dialógico dar-se-á pela aplicação de pressupostos ${ }^{4}$ básicos necessariamente integrados no processo da pesquisa:

a) da dimensão alteritária - na qual o pesquisador, ao mesmo tempo que participa responsavelmente do evento observado, constituindo-se parte dele, mantém também uma posição exotópica que lhe permite o encontro com o outro: colocar-se no lugar do outro 
e depois voltar ao seu lugar, como pesquisador, e com o seu excedente de visão dar-lhe forma e acabamento;

b) da tensão dialética - instaurada no encontro discursivo de diversas consciências, ou seja, entre pesquisador e autores-filósofos pesquisados;

c) da responsividade - observável entre enunciados (de um mesmo texto e entre textos diversos), mediante a apreensão das relações de sentido advindas dos diálogos retrospectivos e prospectivos entre diversos textos (discursos), do encontro dos textos (discursos) e dos contextos, entre o já dado (conhecido) e o criado (que está se dando a conhecer).

\section{Situando o problema da subjetividade e da intersubjetividade}

Husserl (2012), ao referir-se à crise das ciências europeias, sugere que se trata não apenas de uma crise existencial da civilização europeia, que abandonara sua matriz filosófica, mas, sobretudo, de uma crise da subjetividade, do ser sujeito em geral, sobre o qual a filosofia, até então, não encontrara uma compreensão adequada, propondo, como alternativa, a fenomenologia transcendental (ciência da essência do conhecimento), enquanto fonte primeira de toda a significação. No contexto dessa obra, é introduzido o conceito mundo da vida, entendido como horizonte pré-científico do sentido prévio a toda e qualquer idealização científica, o que pressupõe contemplar o mundo da doxa, termo cunhado por Husserl para designar uma rede inter-relacionada de crenças e posicionamentos que compreende a atitude natural e cotidiana da vida pré-científica, próprias da práxis humana.

Nesse sentido, a crise da ciência consistiria justamente na "perda da sua significação para a vida" e caberia, à filosofia, "reatar a ligação da ciência [...] com as evidências significativas para a vida" (HUSSERL, 2012, p. 7). Tais evidências encontram-se, segundo Husserl, no mundo da vida, da intersubjetividade e do corpo. Embora para a fenomenologia, o ponto de partida seja sempre a consciência individual e, portanto, seu foco de investigação seja a vivência individual, é preciso lembrar que a proposta de Husserl é a de uma fenomenologia transcendental cuja constituição do mundo realiza-se na consciência ${ }^{5}$ transcendental. Não obstante, o conteúdo das vivências não está na dependência de minha consciência individual, visto que dentre os objetos vivenciados no mundo encontram-se outros egos. Assim, quando o sujeito opera a redução transcendental, ou seja, a suspensão sobre qualquer conhecimento para ater-se à consciência pura, ao mesmo tempo em que se percebe, por meio de sua corporeidade, como um agente que conhece, percebe-se também como membro de uma comunidade de outros egos, de outras consciências transcendentais com as quais se relaciona. 
No âmbito de uma fenomenologia transcendental, o desafio que se colocava, para Husserl, era o de encontrar uma racionalidade adequada para a compreensão dos fenômenos significativos da existência humana e, para esse fim, propôs uma ontologia do mundo da vida, ou seja, uma ciência eidética (da essência) que possibilitasse o conhecimento do fenômeno homem concreto, histórico e social cuja evidência fenomenológica não podia remeter a certezas absolutas, mas sim "a um projeto de compreensão do sentido num horizonte infinito" (HUSSERL, 2012, p. XVI).

Quanto a Heidegger (2010a), podemos observar que, em Ser e Tempo, o parágrafo sétimo é intitulado $\mathrm{O}$ método fenomenológico da pesquisa, e que a tradução inglesa, On time and being (1972), inclui o texto Meu caminho para a fenomenologia, o que parece indiciar a existência de um projeto fenomenológico próprio, ainda que o filósofo assuma, com certa veemência, a máxima husserliana do retorno à coisa mesma. Não é nosso propósito aqui fazer uma análise das diferenças entre ambas as propostas, mas lembrar que a questão fundamental de Ser e Tempo é a recolocação da pergunta pelo ser que a filosofia (metafísica) teria relegado ao esquecimento.

Nesse sentido, cabe lembrar que o contexto no qual Husserl (2012) formula sua máxima não é o mesmo daquele de Heidegger (1972, 2010a), ou seja, não há, no primeiro, uma preocupação de uma ontologia fundamental que pense a relação ser-ente. Enquanto que a preocupação de Husserl (2012) era a de trazer os fenômenos, tais como são ou se apresentam no mundo, para a consciência, em seu estado puro, enquanto manifestação fenomenológica intuitiva, ${ }^{6}$ Heidegger (1972, 2010a) afasta-se do método fenomenológico husserliano, voltado para a vida consciente, para ocupar-se, não de uma estrutura abstrata de um ente transcendental, mas da compreensão do ser do Dasein humano. Trata-se, pois, de um Dasein que só pode manifestar seus modos de ser ontológicos no homem concreto. Na perspectiva heideggeriana (HEIDEGGER, 1972, 2010a), o sentido do ser não coincide com o ente, pois o que se busca são justamente as coisas que se opõem às descobertas aparentemente verificadas, ou, em outras palavras, aquilo que, na maioria das vezes, não se mostra diretamente, mantendo-se velado ao que se mostra, ou seja, o ser do ente.

Segundo Heidegger (1972, 2010a), o mundo da vida é essencialmente o horizonte do sentido, e é a partir dele que cada ser humano constrói sua unicidade: a essência do ser-aí (Dasein) está na sua própria existência; trata-se de um dever existencial de ser responsável por si mesmo, de elaborar a si mesmo na vida fática, na dependência constitutiva dos entes que compreendem a totalidade do real e pelos quais também é responsável. Para chegar à verdade do ser, Heidegger propõe uma analítica existenciária cuja tarefa será demonstrar que qualquer tentativa de partir de um eu e sujeito 
acaba por comprometer seriamente $o$ fenômeno da pre-sença.

O filósofo segue afirmando o primado da existência frente à essência, fazendo uso do termo existencial para caracterizar o Dasein, em contraposição às chamadas categorias das ciências positivas. As características ontológicas da existência chamam de existenciais à medida que se determinam pela existencialidade, sendo nitidamente diferenciáveis das determinações ontológicas dos entes (categorias), que não têm o modo de ser da pre-sença (HEIDEGGER, 2010a). Desse ponto de vista, o homem só pode revelar-se na relação ontológica ser-ente e não por meio de uma relação cognitivo-científica (categorial) com os entes.

Dessas passagens de Ser e Tempo (HEIDEGGER, 2010a), pode-se observar que o filósofo desconstrói a ideia de sujeito e, portanto, de subjetividade do pensamento ocidental, afirmando sua afiliação a um projeto ontológico de existência. Tal projeto estende-se a forma como vai conceber a linguagem, pois, conforme reiterado na obra Carta sobre o humanismo (HEIDEGGER, 2010c), é o Ser que está na linguagem: "a linguagem é particularmente a casa do Ser" (HEIDEGGER, 2005, p. 81), o que equivale a dizer que o ser habita um mundo já ocupado pela linguagem. Trata-se, pois, de um ser reflexivo, que não se confunde com um sujeito (no sentido cartesiano) nem com um eu (ego), mas um inter-sujeito, um ser-aí, um ser-no-mundo, um ser-com-os-outros.
No parágrafo 31 de Ser e Tempo, Heidegger (2010a) apresenta a noção de compreensão (Verstehen) e propõe que o sentido, do ponto de vista ontológico, seja precedido pela ação de compreender. Trata-se do sentido que só pode ser encontrado na intersubjetividade, no mundo compartilhado, com os recursos de compreensão que o Dasein vai lançar mão na sua interação com os outros. Em Heidegger, essa relação ser e mundo é ilustrada por meio de um grupo de existenciais, entre eles, a compreensão, a interpretação, o discurso e a situação afetiva que compreende o modo de nos encontrarmos e sentirmos no mundo. Para ele, o falar é simultâneo ao processo de estar no mundo e da compreensão, tornando-se linguagem no ato conjunto que reúne os existenciários, anteriormente referidos, para ser pronunciado e assim ganhar existência, pois falar é existir: "a fala é linguagem existenciária" ("die Rede ist existenzial Sprache") (HEIDEGGER, 2010a, p. 180).

Fazemos um contraponto de Heidegger com o filósofo dinamarquês Soeren Kierkegaard, uma vez que existem evidências que a sua ontologia tenha sido fonte de inspiração para Ser e Tempo, conforme assevera o também filósofo dinamarquês Poul Lübcke (2013), em palestra proferida no Congresso Kierkegaard 200 anos depois, ao sugerir que os pressupostos ontológicos de Kierkegaard constituem um conjunto de condições necessárias - e frequentemente não 
percebidas - para o seu pensamento existencial.

Enquanto Kierkegaard (2013) radicaliza a centralidade do conceito de existência, como aspecto não meramente regulativo, mas constitutivo das categorias fundamentais dos problemas filosóficos, Heidegger (2010a), em Ser e Tempo, embora tivesse assumido que a essência é a existência, não pretendeu, com isso, estabelecer uma filosofia da existência (existencialismo): seu tema era a verdade ou o sentido do ser no âmbito da existência humana, de pensar a existência indo além da existência. Já para Kierkegaard,

[...] o pensamento objetivo é indiferente ao sujeito que pensa e à sua existência”, enquanto o subjetivo está "essencialmente interessado em seu próprio pensamento, já que existe nele (2013, p. 76).

Nesse sentido, conforme Kierkegaard (2013, p. 130), é a existência que abre espaço entre o sujeito e o objeto, entre o pensar e o ser, já que o puro pensar, objetivamente compreendido, encontra apenas correspondência com o seu objeto, e a verdade acaba, assim, por resumir-se à concordância do pensamento consigo mesmo. Assevera o filósofo dinamarquês que "o conhecer se relaciona com aquele que conhece", o qual é um "existente" e que "todo o conhecimento essencial tem a ver com a existência" (2013, p. 208).

Nessa abertura, que somente é propiciada pela existência, o tornar-se subjetivo seria a mais alta tarefa posta a qualquer ser humano (KIERKEGAARD, 2013). Assim sendo, "quando se pergunta pela verdade, objetivamente, reflete-se sobre a verdade como um objeto com o qual aquele que conhece se relaciona"; ao contrário, "quando se pergunta pela verdade subjetivamente, reflete-se subjetivamente sobre a relação do indivíduo" (2013, p. 210). Da mesma forma, "objetivamente só se pergunta pelas tarefas do pensamento; subjetivamente pela interioridade" (2013, p. 214). Daí a concluir que "a verdade é a subjetividade" (2013, p. 220).

$\mathrm{O}$ que o filósofo parece ter em mente é uma "ciência" ou "saber existencial" sobre o ser de um ente não-idêntico, em devir. Esse tipo especial de saber, no entanto, diferencia-se da ciência tradicional tal como entendida a partir da matriz hegeliana da Wissenschaft. Efetivamente, aquele que é existente - referindo-se ao pensador subjetivo - o faz pensando em sua existência e investindo no seu devir. Fazendo uma correlação entre o pensador subjetivo, em devir, e a linguagem, afirma que alguém só tem estilo quando nunca deixa algo pronto, mas, ao contrário, "agita as águas da linguagem" de forma que até "a expressão mais cotidiana" brote "com a originalidade de um recém-nascido" (KIERKEGAARD, 2013, p. 89).

No contexto do pensar objetivo, Kierkegaard (2013, p. 138-139) vai fazer uma crítica ao saber histórico universal, que cada vez mais tentaria concentrar todo o saber, reduzindo-o a categorias como o "grande", o "importante/significativo", aos quais qualquer um (seja 
ele bom ou malvado) teria acesso. Não obstante, nenhum ser humano teria a garantia de tornar-se histórico-universal. Daí a reivindicar que a ética e o ético têm uma exigência irrecusável sobre a existência individual, pois só o existir possibilita uma preocupação ética (2013, p. 140). Nesse sentido, Kierkegaard prioriza o ético, ou seja, o tornar-se subjetivo em relação ao histórico-universal: "o tornar-se subjetivo deveria dar, a pessoa, muito o que fazer enquanto ela viver" (2013, p. 170). Ele segue afirmando que “[...] a reflexão objetiva volta-se para dentro, em direção à subjetividade e quer, nesta interiorização, ser a [reflexão] da verdade [...]" (2013, p. 207).

Nesse sentido, procuraremos demonstrar que o mundo da vida, referido por Husserl (2012), e a existência, referida por Heidegger (1972, 2010a) e Kierkegaard (2013), encontram ressonância em Bajtin (1997), na obra Hacia una filosofia del acto ético, para uma abordagem ontofenomenológica do acontecimento do ser calcada na vida vivida/existência, abrindo espaço entre o sujeito e o objeto e entre o pensar e o ser ou, em outras palavras, para o desenvolvimento e a recriação da (inter)subjetividade humana.

É, pois, no âmbito da discussão acerca da força da linguagem, do ato ético, que participa do acontecimento do ser, no mundo, que, segundo Bajtin (1997), coloca-se a tarefa da filosofia, que é a de analisar esse acontecimento no mundo, no qual "o ato toma consciência de si mesmo e no qual se desenvolve". Tal filosofia, assevera ele, "não pode gerar conceitos, postulados e leis acerca deste mundo [...] mas só pode ser uma descrição, uma fenomenologia do mundo do ato ético" (1997, p. 39). Trata-se, pois, de um acontecimento que só pode ser descrito participativamente.

De acordo com Bajtin (1997), esse mundo-acontecimento não é tão somente o mundo do ser que já está dado e conhecido como "algo diante dos nossos olhos", como também afirmava Heidegger (2010a), mas é algo que, no dado, ainda está para ser alcançado. Ora, tal assertiva parece sugerir que o mundo, referido por Bajtin, não é aquele que se realiza na consciência transcendental, enquanto um puro ato de representação, a exemplo de Husserl, já que Bajtin refere-se também "ao mundo-do-acontecimento" (1997, p. 39-40), ou seja, o mundo no qual o ser é desvelado e que não coincide com o ser em geral com o qual se ocupou a metafísica, de um ser que já está de antemão dado e conhecido.

Trata-se do ato que possui o ser da vida singular e unitária, orientando-se nele, embora, assim procedendo, o faça em sua totalidade, incluindo "o seu conteúdo semântico bem como sua facticidade efetiva e singular" (BAJTIN, 1997, p. 36). Isso porque o ato, segundo o autor, quando realizado, vê, de seu interior, tanto "um plano único, um contexto unitário" - que remete a um significado teórico -, como também "a facticidade histórica e o tom emocional e volitivo" (BAJTIN, 1997, p. 36). Não obstante, 
Bajtin enfatiza que "o acontecimento, em sua totalidade, não pode ser transcrito em termos teóricos" sem que se perca "o sentido do seu acontecimento" (1997, p. 38), já que "a categoria da vivência do mundo real do ser - enquanto acontecimento -, é a categoria da unicidade" (1997, p. 51). Isso significa que um objeto existente, no mundo, só pode ser vivenciado em correspondência com a minha própria singularidade.

Assim:

[...] tudo o que pode ser efetivamente vivido, vive-se como algo dado e como algo ainda a ser determinado, [...] tem um tom emocional e volitivo e estabelece comigo uma relação ativa na unidade do acontecer que nos abarca (BAJTIN, 1997, p. 40).

Segundo o autor, "esse tom emocional e volitivo é um momento inalienável do ato ético" (BAJTIN, 1997, p. 40), incluindo tanto o pensamento abstrato como aquele que se realiza efetivamente no ser e, portanto, participa do acontecimento.

Esse mundo do acontecimento também é estendido à palavra vivente, que

[...] ignora um objeto plenamente dado, pois no momento que me pus a falar dele, que estabeleci uma relação interessada e ativa, ela não designa mais apenas um objeto como uma certa presença, mas é marcada pela entonação (BAJTIN, 1997, p. 40).

Embora pleiteando que somente o ato ético, por sua natureza responsável, daria conta tanto do geral como do individual, do real e do ideal, reafirma que somente por meio dele há uma "saída para a singularidade de uma vez e para sempre" (BAJTIN, 1997, p. 37).
Nesse sentido, há uma aproximação a Heidegger (1972, 2010a) em dois aspectos: 1) na postulação de uma ontologia fundamental que pense o ser na sua facticidade histórica, ou seja, na transitoriedade do acontecimento, no mundo da vida; 2) na postulação de que o sentido e/ ou a verdade do ser (pravda) é decorrente do ato de pensar, de um sujeito, em sua unicidade e singularidade, que se engaja e compromete, eticamente, na busca da verdade do acontecimento do ser.

Parece-nos, pois, que os projetos de abordagem do acontecimento do ser, em Bajtin (1997) e Heidegger (1972, 2010a, 2012), corroboram com o pensamento kierkegaardiano de que, de fato, é a existência que abre espaço entre o sujeito e o objeto, entre o pensar e o ser. Fazendo uma analogia com a afirmação de Kierkegaard, de que "todo o conhecimento essencial tem a ver com a existência" (2013, p. 208), poderíamos dizer, com Bajtin e Heidegger, que todo o conhecimento acerca do acontecimento do ser que vive na unicidade e singularidade do ato só pode ser encontrado na existência.

Referindo-se ao mundo como conteúdo do pensamento científico, Bajtin observa que "[...] este mundo não pode abrir-se para o mundo único real do próprio conhecer" (1997, p. 20), e que a única saída é o ato ético porquanto o mesmo concretiza-se no ser através de mim e de outros.

Heidegger (2012) adverte que até mesmo a tão propalada vivência do eu-tu 
ainda pertenceria ao âmbito metafísico da subjetividade, já que, na filosofia e na história, o ser fala diretamente de si mesmo, ou seja, já tem uma compreensão de si mesmo, sua forma de presença no mundo é estável, fazendo coincidir o ser com o ente. Para Heidegger, é preciso questionar o "ter-se-aí do ser-aí enquanto ser, enquanto o como da facticidade e enquanto existencial" (2012, p. 57). Ora, tanto na consciência histórica como na filosofia, o ser-aí é reduzido a um caráter objetivo e na modalidade de um ser permanente, determinado pela cognição, quando devemos questionar o caráter ontológico do ser-aí em sua peculiar mobilidade, ou seja, o como da temporalidade, da facticidade, revelados pelos existenciais na própria existência.

Essa ideia de subjetividade é desconstruída por Heidegger (2012) na referência à hermenêutica da duplicidade (ser/ente), que indicia a forma pela qual o ser-aí mundano significa, tanto em seu contexto fenomenológico como em seu caráter de encontrar-se no mundo. O ser é, antes de tudo, o modo de se dar histórico do homem em determinadas épocas, enquanto projeto que o constitui. Trata-se de um projeto do sentido do ser, o qual transcende a totalidade do ente. Enquanto na metafísica, o ser só pode ser pensando como aquilo que se apropria do homem e o remete a ele, o fato ressaltado na obra Ser e Tempo (HEIDEGGER, 2010a) é que da mesma forma que o homem não existe sem o ser, o ser também não existe sem o homem.
Da mesma forma, Bajtin (1997) reitera que o objeto de uma filosofia moral é o ato ético em sua participação no ser, sugerindo a descrição de sua arquitetônica com base no plano concreto do mundo do ato unitário e singular, cujos momentos constituintes de estruturação são o eu-para-mim, o outro-para-mim e o eu-para o outro, em torno dos quais se encontram dispostos todos os valores da vida real e da cultura.

\section{Considerações finais}

As questões levantadas neste estudo parecem sinalizar a existência, entre os filósofos aqui mencionados, de uma inquietação filosófica extremamente produtiva, que os levou, cada um a seu modo e a seu tempo, a pensar em um projeto de conhecimento bastante distinto daquele que conhecemos nas ciências positivas. Tais projetos, especialmente em Bajtin e Heidegger, os quais tentamos compreender em suas vertentes fenomenológica-ontológica e hermenêutica, modificam radicalmente nossa visão sobre as formas de conhecimento, especialmente em relação aos fenômenos de linguagem - não mais considerados como objetos, pois incluem noções de sujeito, subjetividade e intersubjetividade -, de noção da própria história/historicidade, que não pode mais ser confundida com uma história geral de fatos passados, mas, deve-se pensar a história do acontecimento do ser que só pode ser devidamente apreendida 
no curso da existência, da vida de fato vivida; da forma de se pensar a noção de linguagem como aquela que detém a guarda tanto do ser das coisas como também do modo de acontecer do evento, na medida em que ela circunscreve o campo da nossa possível experiência no mundo; da noção de sentido, se considerarmos que a compreensão dos fenômenos de linguagem que se pretende é aquela que só pode ser encontrada no dever-ser do ato responsavelmente vivido e no ser-aí (Dasein), no acontecimento do ser e do ser-com-os-outros, ou seja, trata-se daquilo que a própria vida dá a entender, um mundo impregnado por tonalidade emocional/afetiva e volitiva.

Pensar o ser como o princípio para a abertura para o mundo significa pensar a verdade do ser, como um acontecimento, na perspectiva de sua história existencial, equivale a retomar a pergunta acerca da origem do sentido e as vias de acesso à realidade que toda a linguagem e, por conseguinte, todo o discurso/texto/ enunciado comportam; reconhecer que existem diferenças fundamentais entre as tarefas da razão (logos) e do pensamento se considerarmos que uma coisa são os conhecimentos científicos e filosóficos que detemos sobre a linguagem e outra são as experiências pensantes que fazemos com ela; para se fazer uma experiência pensante, com a linguagem, não se pode permanecer em uma pré-compreensão de um mundo já dado, conhecido, explicado, de um sentido estabilizado. A compreensão que se pretende é aquela que só pode ser encontrada no dever-ser do ato responsavelmente vivido e no acontecimento do ser, o que traz implicações éticas sobre as formas de se chegar ao conhecimento.

\section{Paths of the subjective thought to become (inter)subjective: a philosophical approach}

\begin{abstract}
This article aims to examine, in the context of a philosophical approach to language, the ways of subjective thought to become (inter)subjective. To this end, we put into dialogue the philosophical ideas of E. Husserl, M. Bajtin, M. Heidegger and S. Kierkegaard. The issues raised are suggestive of the existence of knowledge projects which are very different from what we know in the positive sciences which radically change our view of the forms of knowledge, of language phenomena, of otherness, which include the notions of subject, subjectivity and (inter) subjectivity; the notion of the history/ historicity; the way of thinking about the notion of language as something that holds custody of both being of things but also the way of happening of the event; the sense of meaning, which can only be found in the must-be of the act responsibly lived and in the be-there (Dasein), in the event of being and being-with-the-other(s).
\end{abstract}

Keywords: Language philosophy. Otherness. Subjective thinking. (Inter)subjectivity. 


\section{Notas}

1 O modo pelo qual o Dasein dá-se a cada vez, Heidegger (2012) chama de sua facticidade. O conceito de facticidade inclui o ser-no-mundo de um ente intramundano capaz de se compreender como lugar no seu destino para o ser do ente que se encontra no interior de seu próprio mundo.

2 Heidegger (2012), em sua analítica existencial, refere-se a três modos de ser constitutivos da abertura do Dasein: compreensão, disposição (situação afetiva) e discurso.

3 A facticidade entendida como ser-aí próprio em seu aí hoje, ocasional (HEIDEGGER, 2012).

4 Esses pressupostos foram adaptados de sugestões de Sobral (2005, p. 106), Freitas (2003, p. 27-32) e Amorim (2003, p. 11-25), em estudos nos quais os autores tratam de questões epistemológicas relevantes para a pesquisa científica nas ciências humanas.

5 A vida da consciência é sempre intencional: tudo o que passa pela consciência do eu transcendental (é o fato do mundo, que ele constitui exatamente enquanto transcendental) tem uma intenção com a qual está intrinsecamente ligado. Toda consciência é consciência de alguma coisa, é um puro ato de representação.

6 A intuição fenomenológica é a tomada de consciência de algo que está fora, é o aparecer, o manifestar-se do objeto para a consciência. O fenômeno é apreendido pelo sujeito cognoscente, que o torna seu. Compreender o mundo é um trabalho realizado por uma consciência alimentada por esse mesmo mundo. Trata-se de uma consciência alimentada pelo mundo, cujos conteúdos vêm das vivências, sendo também retroalimentada pelo mundo, pois os sentidos atribuídos aos objetos são constituídos na relação do eu com os outros.

\section{Referências}

AMORIM, Marília. Para uma filosofia do ato: "válido e inserido no contexto". In: BRAIT, Beth (Org.). Bakhtin, dialogismo e polifonia. São Paulo: Contexto, 2009. p. 17-43.

. A contribuição de Mikhail Bakhtin: a tripla articulação ética, estética e epistemológica. In: FREITAS, Maria Teresa; JOBIN
E SOUZA, Solange; KRAMER, Sônia (Org.). Ciências humanas e pesquisa: leituras de Mikhail Bakhtin. São Paulo: Cortez, 2003. p. 11-25.

BAJTIN, M. Hacia una filosofia del acto ético: de los borradores y otros escritos. Trad. Tatiana Bubnova. Barcelona: Rubi e San Juan; Antrophos, 1997.

FREITAS, Maria Teresa de Assunção. A perspectiva socio-histórica: uma visão humana da construção do conhecimento. In: FREITAS, Maria Teresa; JOBIN E SOUZA, Solange; KRAMER, Sônia (Org.). Ciências humanas e pesquisa: leituras de Mikhail Bakhtin. São Paulo: Cortez, 2003. p. 26-38.

HEIDEGGER, M. A caminho da linguagem. 5. ed. Trad. Márcia Sá Cavalcante Schuback. Bragança Paulista: São Francisco; Petrópolis: Vozes, 2011.

Carta sobre o humanismo. Trad. Rubens Eduardo Frias. São Paulo: Centauro, 2010c.

El ser y el tiempo. 2. ed. Trad. José Gaos. Buenos Aires: Fundo de Cultura Econômica, 2010a.

Fenomenologia da vida religiosa. Trad. Enio Paulo Giachini, Jairo Ferrandin e Renato Kirchner. Bragança Paulista: São Francisco; Petrópolis: Vozes, 2010b.

On time and being. Trad. Joan Stambaugh. New York; Hagerstown; San Francisco; London: Harper \& Row, 1972.

Ontologia: (Hermenêutica da facticidade). Trad. Renato Kirchner. Petrópolis: Vozes, 2012.

HUSSERL, E. A crise das ciências europeias e a fenomenologia transcendental. Trad. Diogo Falcão Ferrer. Rio de Janeiro: Forense, 2012.

KIERKEGAARD, S. A. Pós-escrito às migalhas filosóficas. Trad. Álvaro Luiz Montenegro Valls e Marília Murta de Almeida. Petrópolis: Vozes, 2013. v. 1. 
LÜBCKE, P. O legado filosófico de Kierkegaard. Entrevista. Revista do Instituto Humanitas Unisinos, n. 480, 2013. Disponível em: $<$ http://www.ihuonline.unisinos.br./media/ pdf/IHUOnlineEdicao418.pdf>. Acesso em: 10 nov. 2015.

SAMPAIO, M. C. H. Origens filosóficas da ética em Bakhtin: re-leituras da metafísica e da fenomenologia ontológico-hermenêutica. In: ZANDWAIS, Ana (Org.). História das ideias: diálogo entre linguagem, cultura e história. Porto Alegre: Ufrgs; Passo Fundo: UPF Editora, 2012. p. 192-215.

SAMPAIO, M. C. H.; ARAÚJO, K. D. de S.; MACEDO, E. B. I. de. Bakhtin e Heidegger: caminhos para a compreensão e interpretação do acontecimento do ser. Bakhtiniana, São Paulo, v. 10, n. 3, p. 186-204, 225-242, 2015. Disponível em: <http://revistas.pucsp. br.>. Acesso em: 2 nov. 2015.

SOBRAL, Adail. Ético e estético: na vida, na arte e na pesquisa em Ciências Humanas. In: BRAIT, Beth (Org.). Bakhtin conceitos-chave. São Paulo: Contexto, 2005. p. 103-121. 